\title{
Los vínculos entre religión y política a la luz del debate sobre matrimonio para parejas del mismo sexo en Argentina
}

\section{The links between religion and politics in the light of the debate on marriage for same-sex couples in Argentina}

\author{
Daniel Jones* \\ Juan Marco Vaggione**
}

\begin{abstract}
Resumo: O objetivo geral desse artigo é colaborar na discussão sobre as relações entre religião e política tomando os desafios abertos pelo ingresso da sexualidade na arena pública-política. O objetivo específico é analisar as intervenções das lideranças e instituições católicas e evangélicas no debate sobre o reconhecimento legal dos casais do mesmo sexo na Argentina. Para dar conta desses posicionamentos, analisamos seus documentos oficiais e suas declarações na mídia. Entre os nossos resultados, destaca-se o pluralismo no interior dos campos católico e evangélico e a complexidade discursiva das intervenções políticas de atores religiosos.
\end{abstract}

Palavras-chave: religião; política; sexualidade; matrimônio; homossexualidade

\begin{abstract}
The article general purpose is to contribute to the discussion on the relationship between religion and politics, by considering the new challenges opened by sexuality irruption in the public sphere. The specific aim is to analyze catholic and evangelical participation during the legal recognition of same-sex couples in Argentina. To reconstruct their positions, we analyze their official documents and their public media declarations. Among our findings, we emphasize the pluralism within the catholic and evangelical fields and the discourse complexity of religious actors in their political interventions.
\end{abstract}

Keywords: religion; policy; sexuality; marriage; homosexuality

\footnotetext{
*Consejo Nacional de Investigaciones Científicas y Técnicas de Argentina (Conicet)/

Universidad de Buenos Aires. < danielprotestantes@gmail.com>.

**Conicet/Universidad Nacional de Córdoba. <juanvaggione@yahoo.com>.
}

\begin{tabular}{|l|l|l|l|l|l|}
\hline Civitas & Porto Alegre & v. 12 & n. 3 & p. 522-537 & set.-dez. 2012 \\
\hline
\end{tabular}




\section{Introducción}

Luego de décadas de activismo, los movimientos feministas y por la diversidad sexual han logrado impactar en las legislaciones y políticas públicas, adquiriendo creciente legitimidad el paradigma de los derechos sexuales y reproductivos (DDSSRR) (Corrêa y Petchesky, 2001; Raupp Ríos, 2004). Este impacto inaugura una nueva forma de comprender la política donde dimensiones otrora excluidas de ésta se vuelven relevantes. Desde la década de 1990, la histórica consigna del feminismo "lo personal es político" ha penetrado en la construcción del campo político en América Latina, al lograrse que las formas de regular la sexualidad y la reproducción sean materia de debate público. La discusión sobre la regulación legal de la sexualidad y la reproducción inscribe una concepción de lo político que tensiona los marcos desde los que usualmente se da sentido a lo religioso. La política sexual trasvasa la dicotomía público/privado y evidencia las complejas articulaciones entre lo religioso y lo secular, Iglesia y Estado, derecho y doctrina. Articulaciones que requieren de nuevos marcos analíticos para comprender las influencias religiosas sobre la política, así como de posturas críticas hacia las construcciones normativas sobre lo secular, o lo laico, que caracterizan las agendas académicas y políticas.

En este proceso, los derechos para las personas lesbianas, gays, bisexuales y trans (LGBT) son un eje central. Si bien existen antecedentes judiciales (Vaggione, 2008), recién en el 2002 se sancionó en Argentina y en Latinoamérica la primera ley que reconocía derechos a las parejas del mismo sexo (la unión civil). Ocho años después, Argentina fue escenario de otro cambio legal y político crucial: la aprobación del matrimonio para estas parejas. Focalizándose en el debate que culminó con la sanción del derecho al matrimonio para las parejas del mismo sexo durante el 2010, este trabajo considera dos articulaciones entre lo religioso y lo político que se visibilizaron durante dicho proceso. Por un lado, los modos de intervención de las jerarquías católica y evangélica frente a la reforma del régimen matrimonial. ¿Cuáles son los argumentos de las principales instituciones religiosas para evitar un cambio contrario a su construcción de lo sexual? Este interrogante ilumina los límites de la dicotomía religioso/secular para comprender cómo las instituciones religiosas participan en debates políticos contemporáneos. Por otro lado, la heterogeneidad que caracteriza al campo religioso respecto a la política sexual. Aunque en la mayoría de los estudios lo religioso se plantea como una influencia conservadora sobre la política sexual, este artículo rescata el pluralismo del campo religioso que permite, en algunos casos, considerarlo una fuerza política favorable a la diversidad y libertad sexuales. 


\section{La jerarquía de la Iglesia Católica}

La irrupción de los DDSSRR a la esfera pública confronta de diversas formas a la jerarquía católica. En particular, el rechazo a los derechos de las personas gays y lesbianas se ha transformado en un eje doctrinal y político privilegiado por el Vaticano. La postura contraria a la homosexualidad se rigidizó con la llegada de Karol Wojtyła y Joseph Ratzinger, el primero como Papa Juan Pablo II (desde 1978) y el segundo como Prefecto de la Congregación para la Doctrina de la Fe desde 1981 y como Papa Benedicto XVI desde 2005. En 1986 una carta a los obispos sobre la atención pastoral lamenta "que las personas homosexuales hayan sido y sean todavía objeto de expresiones malévolas y de acciones violentas", pero sostiene que la "inclinación misma (homosexual) debe ser considerada como objetivamente desordenada" (Congregación, 1986), por lo que ya no sólo se estigmatiza el acto homosexual sino también a la persona. ${ }^{1}$ Este endurecimiento doctrinal es simultáneo a una postura pública de la IC cada vez más rígida frente al avance de los DDSSRR. La construcción religiosa transmitida al interior de su comunidad se acompaña de instrucciones para líderes y ciudadanos sobre cómo actuar frente a las reformas legales que reconocen derechos a gays y lesbianas (Congregación, 1992; Congregación, 2003).

De ahí que no sea sorprendente el liderazgo de la IC Argentina en la oposición al reconocimiento legal de las parejas del mismo sexo, en general, y a la modificación del régimen matrimonial, en particular. En abril del 2010, ya ingresado al parlamento el proyecto habilitando el casamiento para las parejas del mismo sexo, la Conferencia Episcopal Argentina (CEA) emitió el documento "Sobre el bien inalterable del Matrimonio y la Familia", que lo defiende como una unión exclusivamente heterosexual. En paralelo, diversas autoridades de la IC se manifestaron contra el proyecto de ley. La cantidad y la amplia cobertura territorial de estos pronunciamientos refuerzan la idea de que fue un tema prioritario y una estrategia monolítica de la jerarquía católica (Sgró Ruata; Rabbia, 2011).

La mayoría de las argumentaciones que la jerarquía católica inscribe en la arena pública para rechazarlo son seculares. Si bien el uso estratégico de justificaciones seculares no es novedoso para la IC, las mismas han devenido el eje central de sus intervenciones contra los DDSSRR, caracterizadas cada vez más por argumentos científicos, bioéticos o legales (Vaggione, 2005). Tanto

Pese a que en 1973 la homosexualidad había sido excluida de los trastornos psicológicos del DSM-III (Manual Diagnóstico y Estadístico de los Trastornos Mentales) por parte de la Asociación Psiquiátrica Americana. 
el documento de la CEA como las manifestaciones públicas de los obispos rechazan al "matrimonio homosexual" retomando dos tipos de justificaciones que el Vaticano rotula como "biológicas y antropológicas" y "jurídicas".

La primera señala la necesidad de complementariedad entre los sexos para conformar un matrimonio y la potencialidad procreativa que debiera tener el acto sexual para ser moral y legal. Por un lado, las parejas homosexuales "no están en condiciones de asegurar adecuadamente la procreación y la supervivencia de la especie humana" (Congregación, 2003). Para la IC sexualidad y reproducción están intrínsecamente unidas por lo que aceptar el matrimonio de dichas parejas implica legitimar un vínculo sexual donde la procreación es considerada una "imposibilidad". Por otro lado, "la ausencia de la bipolaridad sexual crea obstáculos al desarrollo normal de los niños eventualmente integrados en estas uniones. A éstos les falta la experiencia de la maternidad o de la paternidad" (ídem). En consonancia con esta línea vaticana, el argumento del interés superior del niño fue uno de los principales en Argentina contra los derechos para las parejas del mismo sexo. La existencia de investigaciones científicas probatorias de los riesgos para los niños es una de las argumentaciones de mayor peso simbólico, que ha circulado en el ámbito nacional e internacional para demostrar la inconveniencia de esta reforma legal. El otro registro priorizado por la jerarquía católica es el jurídico. El documento de CEA y las declaraciones de obispos y arzobispos afirman, también en base a documentos del Vaticano, que diferenciar en el tratamiento legal no necesariamente significa discriminar: excluir a las parejas del mismo sexo del derecho al matrimonio no implica - como señala el movimiento por la diversidad sexual - un acto de discriminación injusta, ya que "constatar una diferencia real no es discriminar. La naturaleza no discrimina cuando nos hace varón o mujer" (CEA, 2010).

Este desplazamiento estratégico hacia argumentaciones seculares también se manifiesta en la excepcionalidad del uso de argumentos religiosos en sus declaraciones públicas. Entre estas excepciones, ya aprobado el proyecto de reforma del matrimonio en la Cámara de Diputados y a poco del debate en Senadores, se publica una carta de la máxima autoridad de la IC, el Presidente de CEA Jorge Bergoglio, a las monjas Carmelitas Descalzas. La carta implicó un viraje respecto al tono de la jerarquía católica hasta el momento, pues su contenido exclusivamente religioso contrasta con el peso de los discursos seculares previamente ofrecidos. El Cardenal Bergoglio sostiene que no se trata sólo de una discusión política sino que es "la pretensión destructiva al plan de Dios", de la cual el proyecto de ley es un instrumento: "Aquí también está la envidia del Demonio, por la que entró el pecado en el mundo, que 
arteramente pretende destruir la imagen de Dios: hombre y mujer que reciben el mandato de crecer, multiplicarse y dominar la tierra" (Bergoglio, 2010). La carta fue ampliamente divulgada por los medios de comunicación como parte de la postura de la IC hacia el proyecto de ley de reforma del matrimonio y generó un marcado rechazo durante su debate en el Senado (Vaggione, 2011). ${ }^{2}$ El uso de argumentaciones explícitamente religiosas no sólo fue excepcional sino que, incluso, parece no haber servido como estrategia política para sumar a ciudadanos y legisladores contra el matrimonio para parejas del mismo sexo.

\section{Sacerdotes católicos a favor de la reforma legal}

Pese a este posicionamiento fuertemente restrictivo hacia la homosexualidad desde el Vaticano y la jerarquía de la IC Argentina, el campo católico es plural y heterogéneo. El movimiento por la diversidad sexual y el feminista impactaron en sectores católicos que han percibido sus propuestas como coherentes con su tradición religiosa (como reflejan las organizaciones Dignity y Católicas por el Derecho a Decidir).

En el debate sobre el matrimonio, este pluralismo católico se manifestó entre los sacerdotes. Si bien la mayoría y los más poderosos líderes de la IC en Argentina se movilizaron contra la reforma de la ley, algunos sacerdotes llamaron públicamente a apoyarla, contrariando las instrucciones oficiales e inscribiendo una forma alternativa de entender la tradición católica. Más allá de cuánto impacto pueda tener este fenómeno al interior de la IC y en su postura oficial, es relevante políticamente por dos motivos. Primero, estas declaraciones evidenciaron que no sólo entre creyentes católicos sino incluso entre la curia existe un pluralismo sobre la sexualidad: que grupos de sacerdotes apoyen derechos para personas gays y lesbianas tuvo un importante impacto simbólico en el debate, ampliado por la difusión de la prensa. Segundo, estos sacerdotes también marcan un cambio importante respecto de los sectores históricamente progresistas del catolicismo. La teología de la liberación, con una influencia importante en Latinoamérica, ha sido criticada por reforzar una postura patriarcal y conservadora sobre la sexualidad (Vuola, 2002). Sin embargo, estos sacerdotes evidencian que algunos sectores identificados con dicha teología también consideran a la sexualidad y al género dimensiones que estructuran opresión en las sociedades contemporáneas, integrando a su tradición demandas del feminismo y del movimiento por la diversidad sexual.

2 No puede pensarse que su publicación fuera accidental, pues fue difundida por la Agencia Informativa Católica Argentina (Aica) y por el Boletín Eclesiástico del Arzobispado de Buenos Aires, en sus versiones on line e impresa. 
Se manifestaron dos grupos de sacerdotes a favor del derecho al matrimonio para las parejas del mismo sexo. El Grupo Sacerdotal Enrique Angelelli de Córdoba publicó en mayo del 2010 el documento "Aporte al debate sobre modificaciones a la ley de matrimonio civil" escrito por el sacerdote Nicolás Alessio. ${ }^{3}$ Compuesto por 12 sacerdotes, es un movimiento tercermundista con trabajo en los sectores más pobres y excluidos de la población. El otro grupo de sacerdotes, que publicó el documento "Preguntas que nos surgen en la situación actual" apoyando al proyecto de reforma (Presbítero Blanco et al., 2010), pertenece a la Diócesis de Quilmes (Provincia de Buenos Aires), influenciada por su primer obispo, Jorge Novak, quien denunció las violaciones a los derechos humanos por la dictadura militar en Argentina (1976-1983) y le dio a la diócesis una impronta de inclusión a sectores marginados.

Estos documentos presentan tres puntos en común. Primero, tienen como principal objetivo mostrar que la IC no es una institución monolítica con respecto a la sexualidad: "En la Iglesia Católica no hay un 'pensamiento único', hay lugar para la diversidad y la pluralidad" (Grupo Angelelli, 2010). Contra lo sostenido por la jerarquía, afirman: "Entendemos que un legislador puede profesar profundamente su fe cristiana y católica, y, a la vez, con total libertad de conciencia, pensar, definir y actuar distinto a lo que propone la jerarquía eclesial" (Grupo Angelelli, 2010).

Segundo, ambos documentos plantean argumentos principalmente religiosos. Por ejemplo, afirman que la postura oficial de la IC no necesariamente coincide con el mensaje del Evangelio, ya que "si algunos textos de las cartas apostólicas incluyen en sus listas de 'pecados' a la homosexualidad, es sólo para adaptarse a los códigos morales greco romanos (...) pero de ninguna manera expresan una condena a la homosexualidad como tal" (Grupo Angelelli, 2010). Para estos sacerdotes el mensaje de Jesús es compatible con (e incluso favorable a) la redefinición del régimen matrimonial: "Jesús dedica todas sus energías y entusiasmo a predicar 'el reino de Dios', y relativiza de un modo claro y evidente la familia” (Presbítero Blanco et al., 2010). En la misma Biblia que la jerarquía del Vaticano y la IC Argentina basan su exclusión, estos sacerdotes encuentran la justificación para apoyar los derechos de las personas LGBT: "A la luz del evangelio del Buen Samaritano (cf. Lc 10, 25-37) nos preguntamos, ¿cómo podríamos considerarnos discípulos de Jesús sin conmovernos con entrañas de misericordia ante los hermanos y hermanas

3 Por este apoyo, se le inició un juicio canónico a Alessio, que culminó con su suspensión "a divinis", que implica la prohibición de celebración de sacramentos, o sea privarlo del oficio de párroco (Aica, 2011, 18 de marzo). 
excluidos del camino de la vida y la igualdad ante la ley?" (Presbítero Blanco et al., 2010).

Finalmente ambos documentos se distancian del uso del derecho natural de la jerarquía católica: "Citar a la 'ley natural' para oponerse a esta legislación es sólo una posición fijista, dura, congelada, de la realidad pretendida como 'natural', sin entender los complejos procesos culturales" (Grupo Angelelli, 2010). La apelación a lo natural es considerada parte del problema: “¿A qué se llama 'natural' en estas discusiones? ¿No estará aquí una de las dificultades para poder clarificar este debate? 'Ley natural', 'naturaleza', 'orden natural', ¿no son expresiones a ser revisadas y actualizadas?” (Presbítero Blanco et al., 2010).

Recapitulando, si la tendencia de la jerarquía católica es presentar argumentos seculares para justificar su rechazo a los DDSSRR, los sacerdotes católicos progresistas que aquí intervinieron, en cambio, priorizaron argumentaciones religiosas. Este pluralismo al interior del campo católico muestra disidencias en dos sentidos. Por un lado, disiente de la postura religiosa sobre la sexualidad que defienden la jerarquía del Vaticano y de las IC nacionales. La doctrina oficial afirma una concepción restrictiva de la ética sexual, limitada al acto sexual procreativo y unitivo, mientras que estos grupos de sacerdotes entienden al catolicismo como amplio y plural respecto a la sexualidad. Por otro lado, estos dos grupos disienten políticamente al movilizarse en apoyo a la reforma legal contrariando las instrucciones del Vaticano y la CEA. Allí donde la jerarquía pretende representar al creyente católico en oposición al reconocimiento a las parejas del mismo sexo, ellos circulan argumentos para que legisladores y ciudadanos lo apoyen desde la misma tradición religiosa.

\section{Iglesias y federaciones evangélicas}

En Argentina, las iglesias evangélicas constituyen un campo de fuerzas en el que dos polos mantienen disputas por el predominio: uno histórico liberacionista y otro conservador bíblico (Wynarczyk, 2009). Las instituciones del primer polo cuentan con un significativo capital de prestigio por su histórica defensa de los derechos humanos, mientras que el segundo polo (conformado por un sector evangelical - hermanos libres, bautistas - y otro pentecostal) posee la mayor cantidad de creyentes y sostiene un pensamiento moralmente conservador.

En los debates sobre el reconocimiento legal a las parejas del mismo sexo las instituciones evangélicas histórico liberacionistas han apoyado esta ampliación de derechos, mientras que las conservadoras bíblicas la han 
rechazado. Sus discursos públicos se dan principalmente en los registros religioso y jurídico, siendo muy acotado el uso de discursos científicos (sean biológicos, médicos, psicológicos o de ciencias sociales).

En cuanto al discurso religioso, las instituciones conservadoras refieren a pasajes de la Biblia que presentan a la homosexualidad de modo negativo y al matrimonio como un pacto exclusivamente heterosexual (Iglesia Evangélica Luterana de la Argentina (Iela, 2010). La cita bíblica leída literalmente funciona como fuente de autoridad y califican de "falsas enseñanzas" a las "exégesis de las Sagradas Escrituras cuya hermenéutica intenta establecer que la Biblia no condena la homosexualidad o que en algunos casos aun la aprueba" (Alianza Cristiana de Iglesias Evangélicas de Argentina (Aciera, 2003). Al igual que en el catolicismo conservador, es nodal la distinción entre pecado y pecador, al rechazar la práctica homosexual (pecado) y ofrecer "liberación" y "restauración" a los homosexuales (pecadores), quienes deben mantenerse abstinentes y arrepentirse (Aciera, 2010a; Iela, 2010).

Las iglesias históricas liberacionistas también apelan al discurso religioso en estos debates, pero critican el tipo de uso de parte de los cristianos que condenan la homosexualidad: cuestionan el literalismo bíblico (Iglesia Evangélica del Río de la Plata (Ierp), 2000), el abuso de pasajes breves (Iglesia Evangélica Metodista Argentina (Iema), 2010b) y el anacronismo de aplicar categorías actuales al contexto bíblico (Iglesia Evangélica Valdense del Río de la Plata (IEVRP), 2010). En contraposición, plantean principios doctrinales nodales del protestantismo o del cristianismo en general, como la salvación por la sola gracia, la sola fe y el solo Cristo (Ierp - Iglesia Evangélica Luterana Unida (Ielu), 2010), y el mandamiento del amor al prójimo (Ielu, 2003; Iema, 2010b), de los que deducen que los homosexuales no pueden ser excluidos de las comunidades cristianas, ni de la gracia de Dios, ni discriminados en sus derechos. No incluyen citas textuales de la Biblia, pero ofrecen "confrontar" sus afirmaciones con referencias bíblicas (Ierp-Ielu, 2010).

Si bien ambos polos evangélicos utilizan el discurso religioso, lo hacen de modo diferente. El énfasis del sector conservador en la moral sexual desde una mirada bíblicamente legalista - por el "rigorismo ético" del legado evangelical y pentecostal (Wynarczyk, 2009, p. 317) - lo impulsa a intervenir públicamente cuando ve amenazada la "moral cristiana" por una iniciativa política. En contraste, la relectura desde el sector liberacionista de valores religiosos potencialmente emancipadores, como el amor al prójimo y la salvación por la sola gracia, justifica su apoyo a leyes percibidas como reparadoras de injusticias. En ambos casos, las dirigencias religiosas podrían estar amplificando los acentos teológicos, "como estrategia de diferenciación 
frente al lenguaje del 'mundo' (...) y como forma de construir su propio liderazgo" (Algranti, 2010, p. 257).

Ambos polos también justifican sus posiciones en un registro jurídico, a través del discurso de los derechos humanos, en base a los tratados internacionales incorporados a la Constitución Nacional en su reforma de 1994. Mientras que las instituciones liberacionistas enfatizan el derecho a la no discriminación y así apoyan el reconocimiento de las parejas homosexuales (Ierp, 2003), las conservadoras subrayan que esos tratados sólo reconocen como matrimonio a la unión de un varón y una mujer (Aciera, 2009), un argumento también de la jerarquía católica.

Recapitulando, al intervenir en estos debates, los dos polos evangélicos reflejaron distintas concepciones sobre cuál debería ser el vínculo entre religión y política. Para los conservadores bíblicos, otorgar el derecho al matrimonio a las parejas homosexuales agudizaría un alejamiento del orden social y jurídico respecto de la moral cristiana, presentada como una moral única y clara, eterna e invariable, fundada en la inerrancia de la Biblia, que debe leerse de modo literal. ${ }^{4}$ Este razonamiento de evangélicos es cercano al de católicos sobre un derecho natural (coincidente con los valores cristianos), que al derecho positivo sólo le corresponde reconocer. Ampliar el derecho al matrimonio sería un intento de establecer "un nuevo orden social apartado de los fundamentos del cristianismo" y, frente a éste, se atribuyen la misión profética de "alertar sobre el pecado" y "tomar autoridad espiritual sobre autoridades" (Aciera, 2010b), es decir, tutelar el orden jurídico civil para garantizar que refleje ciertos valores cristianos.

Las iglesias históricas liberacionistas apoyan el derecho al matrimonio para las parejas homosexuales valorando "positivamente toda iniciativa tendiente a reparar situaciones de injusticia y discriminación sufridas por minorías en nuestra sociedad" (Ierp-Ielu, 2010) y celebrando este derecho por preservar la libertad y dignidad de todos los seres humanos y posibilitar su

4 Esta moral plantearía una "familia original y naturalmente constituida" (Aciera, 2009), la pareja heterosexual monógama, unida en matrimonio y con hijos, que justifica el rechazo a iniciativas legales que escapan a dicho modelo. La creencia en la Biblia como un texto inspirado completamente y sin error es un denominador común del polo conservador bíblico y una "diferencia central con la mirada que los históricos liberacionistas aplican a la hermenéutica de la Biblia, históricamente situada en paralelo a la empatía con la Modernidad y la razón ilustrada" (Wynarczyk, 2009, p. 47). Cabe distinguir entre el literalismo (como lectura bíblica que se centra en las afirmaciones y los hechos narrados por la Biblia, una escuela hermenéutica presente desde el medioevo), el fundamentalismo (surgido a fines del siglo 19 con la Escuela Teológica de Princeton, que plantea la inerrancia del texto bíblico) y el conservadurismo político religioso, que en el siglo 20 se apropió del fundamentalismo teológico. 
convivencia en una sociedad plural (Iema, 2010b). La no discriminación y el pluralismo son planteados como los criterios para legislar, en contraste con las posturas religiosas "absolutas" o "únicas" que pretenden imponerse a toda la sociedad y las campañas discriminatorias (Iema, 2010a). En Argentina, quizás por su condición de minoría religiosa, las iglesias evangélicas liberacionistas históricamente han cuestionado las propuestas políticas para toda la sociedad justificadas en una moral cristiana (que suele ser la católica oficial), pues suponen "imponer a otros nuestras costumbres, e interpretación de la religión, como absolutos" (Ielu, 2003). En este sentido, se da un contrapunto entre instituciones evangélicas conservadoras y liberacionistas, pues estas últimas tácitamente criticarían a las primeras y a la jerarquía católica por intentar tutelar al Estado en la legislación civil. Así, subrayan que "un estado democrático y pluralista debe estar abierto a escuchar las voces de todos y a decidir con libertad" (Iema, 2010a) y reconocen "la autonomía de la sociedad civil de cualquier teología particular para darse sus propias formas de organización y de consenso surgidos de la práctica democrática" (Ielu, 2003).

\section{Conclusiones}

El relativo éxito del movimiento por la diversidad sexual y del feminismo en la promoción de leyes y políticas públicas sobre DDSSRR implica una nueva etapa en las formas políticas de lo religioso, al desafiar no sólo al rol tradicional de la Iglesia Católica (con su pretensión de monopolizar la definición de la moral sexual y su regulación legal), sino también al proyecto de muchas iglesias evangélicas conservadoras de traducir su crecimiento demográfico en influencia política. El escenario regional muestra que dichos actores religiosos han intensificado su activismo político y diversificado sus estrategias ante estos desafíos.

Precisamente, el artículo se focalizó en las políticas de lo religioso por medio del análisis de la participación de las iglesias evangélicas y católica en el debate sobre el matrimonio para las parejas del mismo sexo en Argentina, retomando sus antecedentes en otras discusiones sobre derechos para personas LGBT. Este debate es una buena vidriera para observar las complejas articulaciones entre religión y política, así como para comparar el accionar de los dos principales grupos religiosos en Latinoamérica y las tensiones entre y dentro de cada uno. Del análisis previo queremos ahondar en dos dimensiones: el pluralismo en los campos católico y evangélico y la complejidad discursiva de las intervenciones políticas de actores religiosos.

En cuanto al pluralismo en los campos católico y evangélico, si bien frente a las iniciativas feministas y por la diversidad sexual ciertos sectores 
religiosos redogmatizan su postura, otros son permeables a su influencia. El debate sobre matrimonio en Argentina evidenció que las religiones pueden ser un factor favorable al cambio social y político, incluso cuando están en juego las formas tradicionales de regular la sexualidad y la familia. Esta apertura de lo religioso a políticas sexuales emancipatorias se manifestó dentro de los campos católico y evangélico aunque de modos distintos, algo comprensible por las diferencias estructurales entre ambos. El esquema piramidal y verticalista de la Iglesia Católica implica una postura oficial definida desde el Vaticano, que se articula en los distintos ámbitos católicos. Una percepción extendida es la del catolicismo constituido por una jerarquía homogénea, fuertemente patriarcal y heteronormativa, que coexiste con un pluralismo de opiniones y prácticas de sus creyentes. Pero este pluralismo también se da entre sacerdotes en forma de disidencia religiosa y política, como ejemplifican los dos grupos de sacerdotes que intervinieron en el debate. Disienten religiosamente, ya que contradicen el magisterio de la IC al proponer una interpretación opuesta a la de la jerarquía, apelando a argumentos del Evangelio o la tradición católica para justificar su apoyo al matrimonio para las parejas del mismo sexo; disienten políticamente al desconocer la autoridad de la jerarquía eclesial para definir el posicionamiento católico en el debate público. Así, estos sacerdotes habilitan simbólicamente para otros creyentes un espacio que permite combinar la identificación católica con el apoyo político a dicho proyecto legal y, eventualmente, a otros DDSSRR.

En el mundo evangélico, en cambio, "la tradición de disidencia de la ética puritana siempre implicó la existencia de distintas visiones del mundo, verificadas en la fragmentación de las denominaciones" (Paiva, 2003, p. 218). Este rasgo ayuda a entender por qué ante el proyecto de matrimonio hubo una pluralidad de posiciones evangélicas oficiales. Mientras que del campo católico sólo se conocieron voces aisladas disintiendo con la jerarquía, en el evangélico varias instituciones de alcance nacional (Ierp, Ielu, Iema) apoyaron públicamente la ley, acarreando una polémica dentro del campo, reflejada en documentos, actos y declaraciones mediáticas. Es decir, este pluralismo evangélico no se reflejó bajo la forma de una disidencia, sino de una polémica e, incluso, de una división política del campo.

Dicho pluralismo religioso fue utilizado por el movimiento por la diversidad sexual para apoyar la demanda del matrimonio, y así romper la imagen de un frente religioso monolíticamente opositor, como pretendió proyectar la jerarquía católica y la dirigencia evangélica conservadora. Desde la Federación Argentina LGBT se promovieron un acto público y un spot publicitario interreligiosos a favor de esta ley, de los que participaron 
sacerdotes y laicos católicos vinculados a la teología de la liberación y autoridades de iglesias evangélicas liberacionistas ${ }^{5}$. Si bien el movimiento por la diversidad sexual tiene una postura predominantemente contraria a la influencia política de lo religioso (debido a la necesidad de confrontar el poder de la IC en la región), en Argentina ha empezado a percibir que el pluralismo religioso puede ser un elemento políticamente estratégico para cambiar las regulaciones legales de la sexualidad. Así, este movimiento se ha permitido trascender la dicotomización entre lo religioso y lo secular al impulsar sus demandas, buscando aliados políticos en el campo religioso.

En conexión con este pluralismo, otro interrogante del artículo es cuáles son los principales registros discursivos que emplean los actores religiosos para debatir el reconocimiento legal de las parejas del mismo sexo. Se destaca la complejidad discursiva de las intervenciones de los sectores religiosos conservadores, caracterizadas por un bifrontismo discursivo: junto a las razones religiosas para preservar un orden sexual tradicional (aquí en defensa del matrimonio como institución exclusivamente heterosexual), dan un espacio creciente a argumentos seculares. La jerarquía católica priorizó estos argumentos al defender una concepción tradicional de familia y de sexualidad mediante justificaciones legales, científicas y antropológicas (relegando a las religiosas). La pregunta sobre cuán abiertas al debate se encuentran estas argumentaciones sigue vigente, pero no puede negarse que las mismas satisfacen las nociones normativas de lo público como espacio vedado para las justificaciones religiosas. Los evangélicos conservadores también desarrollaron una estrategia bifronte, al presentarse públicamente como un actor cívico más y, a la vez, explotar su legitimidad religiosa (Aciera, 2010b). Buscaron potenciar el alcance de su intervención apelando a discursos seculares como el de los derechos humanos y a su creciente caudal demográfico, sin renunciar al capital simbólico de tipo religioso que ostentan en tanto cristianos (Aciera, 2010a), en un país cuya población mayoritariamente se define como cristiana (Mallimaci et al., 2008).

En cambio, al apoyar el reconocimiento legal a parejas del mismo sexo, los evangélicos liberacionistas priorizaron un discurso religioso, con principios doctrinales centrales del cristianismo o del protestantismo (Ierp-Ielu, 2010). También los sacerdotes católicos a favor de esta reforma dieron prioridad al discurso religioso confrontando con la interpretación de la jerarquía eclesial. En ambos casos no cedieron a los religiosos conservadores el monopolio

\footnotetext{
5 El spot está disponible en: <http://www.youtube.com/watch?v=SKWxIbhEtJU>.
} 
del uso de la Biblia en el debate público, sino que presentaron exégesis alternativas para justificar el apoyo cristiano al reconocimiento legal de las parejas homosexuales. Esta incipiente re-biblización de sus intervenciones politicas supone disputar la identidad cristiana (evangélica o católica) a los sectores contrarios al avance de los DDSSRR, que pretenden hegemonizar dichas identidades de enunciación en el debate. Cabe señalar, entonces, que los actores religiosos que apoyaron la ampliación del derecho al matrimonio tuvieron un discurso más homogéneo, con predominio del registro religioso, mientras que los conservadores, aunque también recurrieron a este discurso, priorizaron los registros seculares.

En síntesis, el proceso de reforma de la institución matrimonial en Argentina permite observar las complejas manifestaciones políticas de lo religioso en la escena contemporánea. Por un lado, una alianza entre sectores católicos y evangélicos conservadores contra los DDSSRR, mediante una estrategia discursiva bifronte. Sin renunciar a proponer la única interpretación religiosa verdadera, cada vez más plantean discursos seculares en defensa de un orden sexual tradicional. Por otro lado, este debate visibilizó el pluralismo religioso hacia la sexualidad. Actores católicos y evangélicos apoyaron esta reforma legal utilizando principios cristianos y referencias a la Biblia como argumentos centrales, interrumpiendo la concepción del discurso religioso como necesariamente heteronormativo. Así las cosas, no sólo lo religioso no se ha retirado de la política, sino que incluso las políticas de lo religioso rebasan cualquier comprensión unidimensional, obligándonos a repensar categorías analíticas y normativas desde las cuales frecuentemente se construyó el fenómeno religioso en las academias. Católicos y evangélicos se posicionaron en ambos lados del antagonismo respecto a la reforma del régimen matrimonial, mientras que los discursos religiosos circulantes justificaron tanto la ampliación del espacio legal y cultural para la libertad y la diversidad sexual como su clausura.

En este sentido, aunque el despojar a lo público de sus dimensiones religiosas puede continuar siendo un ideal democrático relevante, las formas en que la heterogeneidad de lo religioso se articularon políticamente en este debate tensiona dicho ideal. Dichas articulaciones ponen de manifiesto la precariedad del trazado de las fronteras entre lo religioso y lo secular cuando se considera la política sexual, precariedad que requiere sino desplazar dicha dicotomía al menos revisar críticamente los aparatos conceptuales e ideológicos desde donde se da sentido a lo religioso en las sociedades contemporáneas. 


\section{Referencias}

ALGRANTI, Joaquín. Politica y religión en los márgenes: nuevas formas de participación social de las mega-iglesias evangélicas en la Argentina. Buenos Aires: Ciccus, 2010.

CORREAA, Sonia; PETCHESKY, Rosalind. Los derechos reproductivos y sexuales: una perspectiva feminista. In: FIGUEROA, Juan Guillermo (ed.). Elementos para un análisis ético de la reproducción. México: Pueg, Puis, Unam, Porrúa, 2001. p. 99-138.

MALLIMACI, Fortunato; ESQUIVEL, Juan Cruz; IRRAZÁBAL, Gabriela. Primera encuesta sobre creencias y actitudes religiosas. Informe de investigación. Buenos Aires: Ceil-Piette/Conicet, 2008.

PAIVA, Angela Randolpho. Católico, protestante, cidadão: uma comparação entre Brasil e Estados Unidos. Belo Horizonte: Editora UFMG; Rio de Janeiro: Iuperj, 2003.

RAUPP RÍOS, Roger. Notas para um direito da sexualidade democrático. In: CÁCERES, Carlos; FRASCA, Timothy; PECHENY, Mario; TERTO JUNIOR, Veriano. (eds.) Ciudadanía sexual en América Latina. Abriendo el Debate. Lima: Universidad Peruana Cayetano Heredia/Ford Fundation, 2004. p. 167-186.

SGRÓ RUATA, María Candelaria; RABBIA, Hugo. El debate sobre matrimonio igualitario en el espacio público argentino. Escena mediática, actores. In: PEÑAS DEFAGO, Angélica; VAGGIONE, Juan Marco (comps.). Actores y discursos conservadores en los debates sobre sexualidad y reproducción en Argentina. Córdoba: Ferreyra Editor y Católicas por el Derecho a Decidir Argentina, 2011. p. 91-126.

VAGGIONE, Juan Marco. Los roles políticos de la religión. Género y sexualidad más allá del secularismo. In: VASSALLO, Marta (comp.). En nombre de la vida. Córdoba: CDD, 2005. p. 137-169.

VAGGIONE, J. M. Las familias más allá de la heteronormatividad. In: MOTTA, Cristina; SAEZ, Macarena (eds.). La mirada de los jueces: género y sexualidad en la jurisprudencia latinoamericana. Bogotá: Siglo del Hombre, 2008. p. 13-87.

VAGGIONE, J. M. Sexual rights and religion: same-sex marriage and lawmakers' catholic identity in Argentina. University of Miami Law Review, Miami, v. 65, p. 935954, primavera 2011.

VUOLA, Elina. Limits of liberation: feminist theology and the ethics of poverty and reproduction. 2. ed. Nueva York: Sheffield Academic Press, 2002.

WYNARCZYK, Hilario. Ciudadanos de dos mundos: el movimiento evangélico en la vida pública argentina 1980-2001. Buenos Aires: Unsam Edita, 2009.

\section{Fuentes:}

ACIERA (2003, 29 de agosto) Homosexualidad: reafirmando valores evangélicos. [En línea]. <http://www.aciera.org/declaraciones.html>. Consulta: 02/06/2009.

ACIERA (2009, 29 de octubre) Postura de ACIERA respecto al matrimonio y la homosexualidad. [En línea]. <http://www.aciera.org/declaraciones.html>. Consulta: $11 / 05 / 2010$. 
ACIERA (2010a, 29 de junio). Por qué rechazamos el proyecto de ley de matrimonio homosexual. Ponencia del Presidente de la ACIERA Rubén Proietti ante el Senado de la Nación con motivo del proyecto de ley de modificaciones al matrimonio. [En línea]. $<\mathrm{http}$ //aciera.org/site_news/index.php?option=com_content\&task=view\&id=127\&It emid=3>. Consulta: 02/08/10.

ACIERA (2010b, 15 de julio). Firmes y adelante. [En línea]. $<$ http://aciera.org/site news/index.php?option $=$ com_content\&task $=$ view\&id $=133 \&$ Itemid $=3>$. Consulta: 02/08/10.

AICA Agencia Informativa Católica Argentina (2011, 18 de marzo). Tribunal Interdiocesano confirma sanción a sacerdote cordobés. [En línea]. <http://www. aica.org/index.php?module=displaystory\&story_id=25801\&format=html\&edition $\mathrm{id}=1448>$. Consulta: 02/08/11.

BERGOGLIO, Jorge (2010, 22 de junio). Carta del cardenal Jorge Mario Bergoglio, arzobispo de Buenos Aires a las Monjas Carmelitas de la arquidiócesis de Buenos Aires. [En línea]. <http://www.aica.org/docs_blanco.php?id=463>. Consulta: 02/08/11.

CEA (2010, abril). Sobre el bien inalterable del matrimonio y la familia. Declaración de la 99a Asamblea Plenaria de la Conferencia Episcopal Argentina. [En línea]. $<$ http:// www.aica.org/docs_blanco.php?id=226>. Consulta: 02/08/11.

CONGREGACIÓN PARA LA DOCTRINA DE LA FE (1986, octubre). Carta a los obispos de la Iglesia Católica sobre la atención pastoral a las personas homosexuales. [En línea]. <http://es.catholic.net/biblioteca/libro.phtml?consecutivo=32>. Consulta: $01 / 02 / 2011$.

CONGREGACIÓN PARA LA DOCTRINA DE LA FE (1992, julio). Consideraciones para la respuesta católica a propuestas legislativas de no discriminación a homosexuales. [En línea]. <http://www.vidahumana.org/vidafam/iglesia/legislativas. html>. Consulta: 01/02/2011.

CONGREGACIÓN PARA LA DOCTRINA DE LAFE (2003, marzo). Consideraciones acerca de los Proyectos de Reconocimiento Legal de las uniones entre personas homosexuales. [En línea]. <http://www.vatican.va/roman_curia/congregations/cfaith/ documents/rc_con_cfaith_doc_20030731_homosexual-unions_sp.html >. Consulta: 01/02/2011.

GRUPO SACERDOTAL ENRIQUE ANGELELLI de Córdoba (2010, 19 de mayo). Aporte al debate sobre modificaciones a la ley de matrimonio civil. [En línea]. $<\mathrm{http}: / /$ elcentroglttb.blogspot.com/2010/05/grupo-de-sacerdotes-enrique-angelelli.html>. Consulta: 01/02/2011.

IELA (2010, mayo). Posición de la Iglesia Evangélica Luterana Argentina sobre el matrimonio homosexual. [En línea]. <http://www.sanlucas.org/modules. php? name $=$ News \&file $=$ article $\&$ sid $=201>$. Consulta: $15 / 06 / 2010$.

IELU (2003, 24 de julio). Diálogo abierto: Ley n ${ }^{\circ} 1004$ de Unión Civil del Gobierno de la Ciudad de Buenos Aires. Comunicado de Prensa de IELU. [En línea]. <http:// www.ielu.org/>. Consulta: 12/06/2009.

IEMA (2010a, 16 de mayo) Declaración sobre la Ley de Matrimonios. Carta del Obispo de la IEMA Frank De Nully Brown. [En línea]. <http://www.iglesiametodista. org.ar/texto_completo.shtml? $x=58126>$. Consulta: 23/05/2010. 
IEMA (2010b, $1^{\circ}$ de julio). Respeto y dignidad. Ponencia del Pastor Carlos Valle en representación del IEMA ante el Senado de la Nación con motivo del proyecto de ley de modificaciones al matrimonio (que no pudo ser leída por no acceder a ello la presidenta de la Comisión respectiva). [En línea]. <http://www.ecupres.com.ar/>. Consulta: 02/07/10.

IERP (2000, abril). Hacia una comunidad de fe inclusiva: enfoque interdisciplinario sobre la homosexualidad. [En línea]. <http://www.iglesiaevangelica.org/men quepensamos.htm> . Consulta: 12/06/2009.

IERP (2003, 25 de julio). "Por un país donde 'quepan todos y todas",. A raíz de la promulgación de la Ley de Unión Civil (Ley $n^{\circ}$ 1004) por el Gobierno de la CABA. [En línea]. <http://www.iglesiaevangelica.org/men_hemosdicho.htm\#civil>. Consulta: 12/06/2009.

IERP-IELU (2010, 31 de mayo). “Matrimonios del mismo sexo”. Declaración de las Iglesias: Evangélica del Río de la Plata (IERP) y Evangélica Luterana Unida (IELU). [En línea]. <http://www.iglesiaevangelica.org/men_hemosdicho.htm>. Consulta: $31 / 05 / 2010$.

IEVRP (2010, 6 de febrero). Acto 15: bendiciones de uniones civiles de parejas con orientaciones sexuales diferentes y bendiciones de parejas de hecho. [En línea]. $<$ http:// www.valdensesdelsur.com/resoluciones-asamblea-sinodal>. Consulta: 12/06/2010.

PRESBÍTERO IGNACIO BLANCO, MARCELO CIARAMELLA, EDUARDO DE LA SERNA (2010, 9 de julio). Preguntas que nos surgen en la situación actual. [En línea]. <www.pagina12.com.ar/diario/sociedad/3-149180-2010-07-09.html>. Consulta: 01/02/2011.

Data de recebimento: 14.08.2012

Data de aprovação: 28.09.2012 